\title{
Terrestrial vertebrate richness of the inhabited Torres Strait Islands, Australia
}

\author{
Tyrone H. Lavery ${ }^{\mathrm{A}, \mathrm{C}}$, Justin J. Watson ${ }^{\mathrm{B}}$ and Luke K.-P. Leung ${ }^{\mathrm{A}}$ \\ ${ }^{A}$ School of Agriculture and Food Sciences, The University of Queensland, Gatton, Qld 4343, Australia. \\ ${ }^{B}$ Institute for Land, Water and Society, Charles Sturt University, Albury, NSW 2640, Australia. \\ ${ }^{\mathrm{C}}$ Corresponding author. Email: tyrone.lavery@uq.edu.au
}

\begin{abstract}
Located between New Guinea and Australia, Torres Strait and its islands provide an opportunity to examine the results of recent isolation on the Australo-Papuan fauna. However, records of the modern diversity of terrestrial vertebrates on the islands remained scattered and poorly documented. Analyses of terrestrial vertebrate inventories and physical island variables can provide insight into pre-existing conditions of the Sahul land bridge and useful strategies for conservation efforts. We collated all available records of terrestrial vertebrates from the 17 inhabited islands and supplemented these with our own systematic surveys. We used Spearman's rank correlation coefficient and nested analysis to determine how species richness relates to physical island variables. We also used cluster analysis to group similar islands based on their vertebrate assemblages. Vertebrate richness is not correlated with Simpson's habitat diversity but is correlated with total number of habitat types, indicating that rare habitats may contribute disproportionately to richness. The archipelago supports a depauperate Australo-Papuan fauna and the assemblages found on smaller islands are subsets of those on larger islands. Island size is the most effective predictor of species richness, and the analysis reveals that geographically related islands support similar suites of species. The frequency with which our surveys added new records to individual island inventories highlights the need for additional sampling in the region.
\end{abstract}

Received 22 April 2012, accepted 28 August 2012, published online 9 October 2012

\section{Introduction}

Studies of the vertebrate fauna of island archipelagos have proven useful for identifying how physical variables can influence species richness (e.g. Mayr and Diamond 2001; Woinarski et al. 2001; Okie and Brown 2009). One general observation that has stemmed from such studies is how species assemblages on oceanic archipelagos vary from those on archipelagos of continental shelf islands. Oceanic islands, having never been connected to larger landmasses, are regarded as supporting assemblages that are a result of colonisation, extinction and speciation rates (e.g. Lawlor 1986). Conversely, continental shelf islands are those previously connected to mainland during Quaternary ice ages. They inherited a mainland fauna and modern assemblages reflect rates of persistence and attrition following their separation (e.g. Lawlor 1986). The species assemblages they support are typically a depauperate subset of those present on the previously connected landmasses (Brown 1971; Patterson and Atmar 1986; Fernández-Juricic 2002; Okie and Brown 2009).

Baseline documentation of the species assemblages on islands is an important conservation objective. Many of Australia's continental shelf islands have acted as refugia for species that have become extinct on the mainland since separation (e.g. Burbidge et al. 1997). Island vertebrate faunas are also quite nonresilient to environmental pressures such as the introduction of invasive species and ecosystem transformation (Woinarski 2010). Furthermore, the species assemblages on continental shelf archipelagos can inform us of past habitat and climatic conditions of land bridges, as well as the fauna communities that were present (e.g. Heaney 1984).

Torres Strait formerly connected Australia and New Guinea as a land bridge and the islands now provide a suitable opportunity to examine the results of recent isolation on Australo-Papuan species. Yet, scientific knowledge of the terrestrial vertebrates of Torres Strait remains in its infancy (Ingram 2008). Accompanying the paucity of species richness data is a scarce interpretation from a biogeographical perspective. Draffan et al. (1983) and Cameron et al. (1984) provide noteworthy syntheses of Torres Strait birds and reptiles respectively. However, mammalian and amphibian richness remain relatively unknown and, in retrospect, the incomplete nature of species richness data used in previous studies may have hampered the conclusions of those authors.

The study reported here uses past records and our own systematic surveys to provide a baseline inventory of the terrestrial vertebrates of the 17 inhabited Torres Strait islands (i.e. those containing permanent human settlements). We aim to determine important physical island variables affecting the species richness of terrestrial vertebrates generally, and birds, 
mammals, reptiles and amphibians individually. The results of this study have implications for conservation and management of terrestrial vertebrate diversity on the Torres Strait islands.

\section{Methods}

Study site

Torres Strait contains 17 islands that support permanent human settlements (Fig. 1). These are scattered throughout the region and are classified into five groups based on geographic location. The Inner group (Kiriri, Muralug, Ngurapai and Waiben) and Near Western group (Badu, Mabyuag and Mua) are islands of acidic volcanic and plutonic continental bedrock that are inundated remnants of the Australian mainland. The Top Western group contains the islands of Boigu, Saibai and Dauan. Boigu and Saibai are dissected remnants of the southern Papuan lowlands. They are also referred to as mud islands as they are of extremely low relief and comprise alluvial muds dominated by mangrove and saline vegetation communities. Dauan is an island formed of continental bedrock, allied to those of the Inner and Near Western groups. The Central group contains Warraber, Poruma, Masig and Iama. Iama is formed of continental bedrock while the remainder are coral cays. The Eastern group (Erub, Mer and Ugar) are islands formed of basaltic lava resulting from Pleistocene volcanic activity (Willmott 1972). Table 1 provides a list of the study islands with accepted traditional and English names, geographical grouping, geological classification, and size. The use of traditional island names has been given preference throughout the text.

Ocean depths average $15 \mathrm{~m}$ throughout Torres Strait (Cameron et al. 1984) and the region has been repeatedly transformed by changes in sea level to form part of the Sahul land bridge that connected Australia and New Guinea. Present-day island formations were established 5800 years ago (Barham 1999; Woodroffe et al. 2000).

Vegetation communities and flora are characteristic of northern Australian and southern New Guinean biomes. The vascular flora is diverse, with 1330 species and 158 recognised communities identified throughout the islands (Stanton et al. 2008).

\section{Species data}

We compiled comprehensive species lists for each of our 17 study islands by reviewing species records available from museum databases and the literature, and supplementing these with our own survey data. From species lists we compiled a presenceabsence matrix where columns represented the 17 islands and rows represented vertebrate species. Species were represented either by a 0 if absent or a 1 if present. Exotic species and records identified to genus only were excluded from the dataset for analyses. Common and scientific nomenclature for reptiles, amphibians and mammals follows WildNet (Queensland Department of Environment and Heritage Protection 2012) and for birds follows Christidis and Boles (2008).

\section{Desktop assessments}

Species records were identified from the Queensland Museum Specimen Registry, the Australian Museum Specimen Registry, scientific papers and reports (Taylor and Horner 1973; Draffan et al. 1983; Mitchell 1988; King et al. 1989; Niland 1996;
McNiven and Hitchcock 2004; Clarke 2004a, 2004b, 2006, 2007; Borsboom 2007; Ingram 2008; Clarke et al. 2010), and bird sightings formally accepted by the Birdlife Australia Rarities Committee (BARC), as listed in their index of decisions and case summaries, Volume 1 (http://www.tonypalliser.com/barc/barchome.html). The Queensland and Australian Museum registries are specimen backed, highly reliable records. Sightings accepted by BARC are peer reviewed and also highly reliable. Data from the published literature are a summation of records made by the authors and desktop reviews, similar to the present study. The collective survey effort of these desktop sources is difficult to determine and undoubtedly varies widely from island to island.

Data from the WildNet database provided by the Queensland Department of Environment and Heritage Protection (http:// www.ehp.qld.gov.au/wildlife/wildlife-online/index.html) were also reviewed. The database incorporates both specimen-backed records and sightings documented by Queensland government staff and environmental professionals. The reliability of sighting records can vary greatly according to the experience of individual observers. However, WildNet also provides a valuable source of records for Torres Strait, where species occurrence data are limited. We thus included these data, but scrutinised all records by cross checking with our other data sources. Twenty-eight species were identified within the study area by WildNet only, so we removed these from the dataset for statistical analyses. The remaining dataset contains 237 unverified WildNet sightings. Error among these is likely to be higher than for other data sources and they potentially contribute to variance in our biogeography analyses.

\section{Vertebrate surveys}

Terrestrial vertebrate surveys were completed with the aim of compiling an overall species list for each island. Each island was surveyed over a single period of five days and four nights. The islands of Iama, Masig, Boigu, Saibai, Dauan and Erub were surveyed between April and November 2007; and Mer, Ugar, Warraber, Poruma, Mua, Badu and Mabuyag between April and August 2009. Incidental records were made on Waiben, Muralug and Ngurupai between 2007 and 2012. Fauna surveys employed pitfall traps, Elliott traps, hair tubes, Anabat ${ }^{\mathrm{TM}}$, spotlighting, bird surveys and active searches for reptiles and amphibians (Sutherland 2006). Species were also recorded opportunistically throughout the survey period from scats, tracks, visual observation and vocalisations.

Pitfall traps consisted of a linear series of five pits set $3 \mathrm{~m}$ apart and connected with a drift fence $15 \mathrm{~m}$ long and $30 \mathrm{~cm}$ high. Pits were constructed from 20-L buckets buried to ground level. Each pitfall line was supplemented by the inclusion of one funnel trap placed at each end of the drift fence. All pitfalls and funnel traps were unbaited. A total of 60 pitfall-nights and 24 funnel trapnights were used on each island.

Small mammal traps (Elliott Type A and Type B, Elliott Scientific, Upwey, Victoria, Australia) were set in linear transects. Traps were set at 10-m intervals and baited with standard Australian small mammal bait (Menkhorst and Knight 2004). A total of 240 trap-nights were used on each island.

Hair funnels (Faunatech, Mount Taylor, Victoria, Australia) were set in linear transects of 10 traps. Traps were placed at 

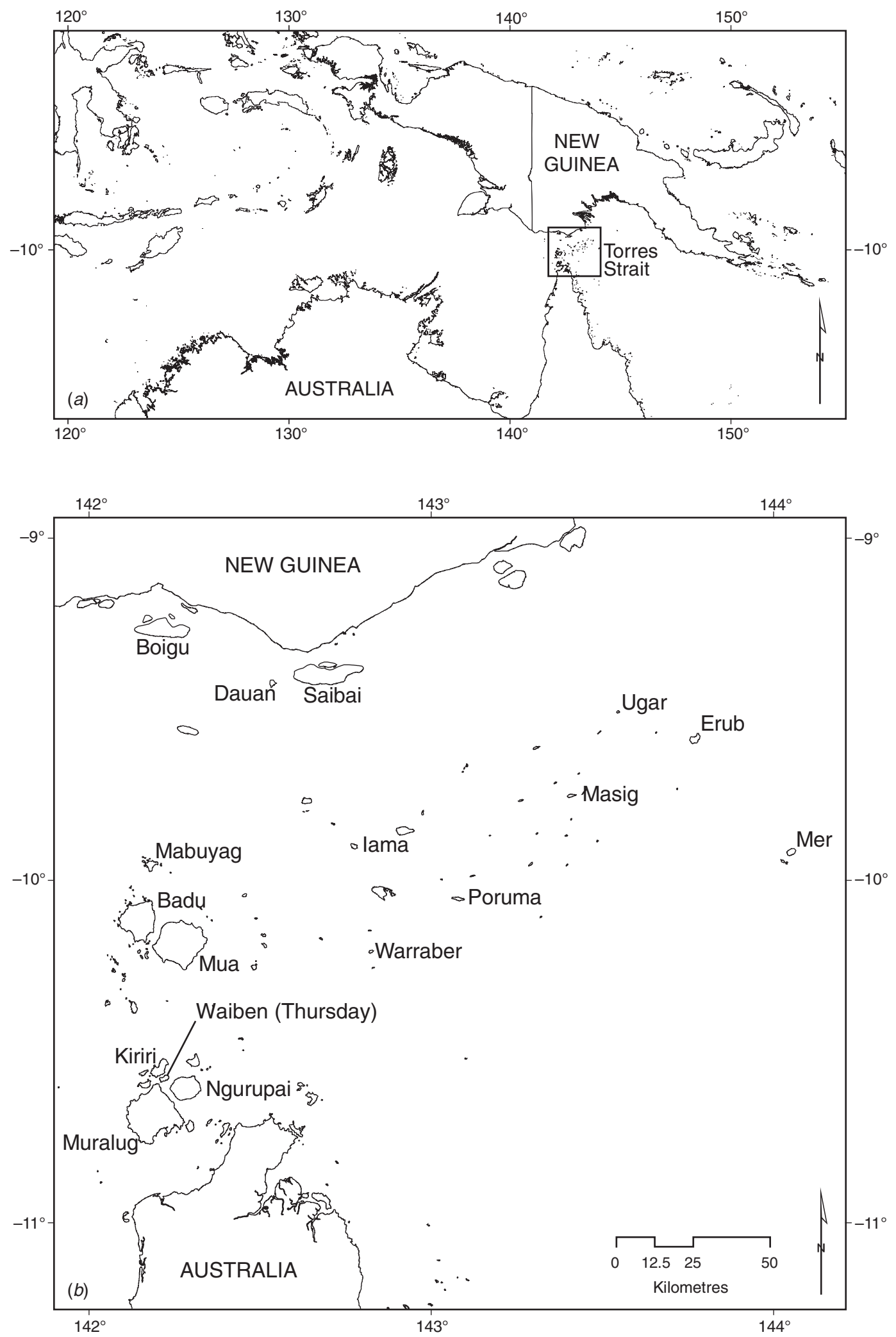

Fig. 1. Location of the Torres Strait islands: (a) general location, (b) study islands. 
Table 1. Inhabited islands of the Torres Strait

\begin{tabular}{llllr}
\hline Group & Traditional name & English name & Geology & Size (ha) \\
\hline Inner & Kiriri & Hammond & Continental Basement & 1400 \\
& Muralug & Prince of Wales & Continental Basement & 20300 \\
& Ngurupai & Horn & Continental Basement & 5300 \\
\multirow{3}{*}{ Near Western } & Waiben & Thursday Island & Continental Basement & 350 \\
& Badu & Mulgrave & Continental Basement & 10160 \\
& Mabuyag & Jervis & Continental Basement & 630 \\
Top Western & Mua & Banks & Continental Basement & 17000 \\
& Boigu & Talbot & Mud & 6600 \\
& Dauan & Mount Cornwallis & Continental Basement & 400 \\
Central & Saibai & & Mud & 10160 \\
& Iama & Yam & Continental Basement & 170 \\
& Masig & Yorke & Coral Cay & 160 \\
& Poruma & Coconut & Coral Cay & 40 \\
Eastern & Warraber & Sue & Coral Cay & 75 \\
& Erub & Darnley & Recent Volcanic & 600 \\
& Mer & Murray & Recent Volcanic & 420 \\
& Ugar & Stephens & Recent Volcanic & 35 \\
\hline
\end{tabular}

intervals of $10 \mathrm{~m}$ and were alternated between ground level and elevated positions ( $2 \mathrm{~m}$ above the ground secured to the trunks of trees). Each tube was baited with standard Australian native small mammal bait mixture (Menkhorst and Knight 2004). A total of 120 hair-tube-nights were achieved per island. Retrieved hair samples were forwarded to Barbara Triggs ('Dead Finish', Genoa, Victoria, Australia) for species identification.

Hand searches for reptiles and amphibians were conducted opportunistically throughout the survey periods. Searches involved over-turning logs and debris and raking leaf litter. A minimum of 10 person-hours were spent actively searching for reptiles and amphibians per island.

Bird surveys were undertaken for a period of $1 \mathrm{~h}$ at dawn on four mornings of the survey period. A minimum of 8 person-hours was spent surveying birds on each island. Opportunistic records were also made throughout the survey period and incorporated into island species lists.

Nocturnal searches for fauna were undertaken by spotlighting. A team of two observers traversed habitats with 50-W halogen spotlights (Powa Beam, Billinudgel, New South Wales, Australia) for a minimum of 4 person-hours per night on each of the four nights. A minimum of 16 person-hours of spotlighting was achieved per island.

Bat echolocation calls were recorded using an Anabat II unit with CF Zero-Crossings Analysis Interface Module (CF. ZCAIM) recording hardware (Titley Scientific, Brisbane, Queensland, Australia). Recording was conducted from a different fixed position on each of the four nights. Analysis of calls was completed by Anabat specialist Greg Ford (Balance! Environmental, Toowoomba, Queensland, Australia) based on Reinhold et al. (2001), Milne (2002) and Leary and Pennay (2011). A level of confidence for call identification was provided as follows: A (definite) - one or more calls where absolutely no doubt about identification of bat; B (probable) - most likely the species named, low probability of confusion with species that use similar calls; and C (possible) - call is comparable with the identified species, but moderate to high probability of confusion with species with similar calls. Only species identified to a confidence level of A or B were added to island species lists.

\section{Variables}

We nominated island size, isolation, geological classification, vegetation and habitat complexity, and human population density as variables that potentially influence species richness. All variables were determined remotely from GIS data layers and from unpublished data from the Torres Strait Regional Authority.

\section{Isolation}

We determined degrees of isolation for each island using two methods. First, we determined the degree of isolation from Australia and New Guinea without consideration of other Torres Strait islands. We used the logarithm of the sum of the distances to New Guinea (dNG) and Australia (dAUS) as a measure of Continental Isolation ( $\mathrm{I}_{\text {continental }}$ ) (Keppel et al. 2010):

$$
\mathrm{I}_{\text {continental }}=\log (\mathrm{dNG}+\mathrm{dAUS}) .
$$

We also used the landscape measure of isolation (Diver 2008) to calculate isolation within $10 \mathrm{~km}$ of each island. We termed this variable Overall Isolation $\left(\mathrm{I}_{\text {overall }}\right)$. The landscape measure of isolation involves calculating the area of a $10-\mathrm{km}$ buffer from the shoreline and the area within that buffer that includes another island or mainland multiplied by 100 :

$$
\mathrm{I}_{\text {overall }}=(\text { Land area within } 10 \mathrm{~km} \text { buffer } / \text { Buffer Area }) * 100
$$

This is, in fact, an inverse measure of island isolation as islands with a greater percentage of land within surrounding buffers are less isolated.

\section{Habitat complexity}

We used three measures of habitat complexity for each island. Vegetation community and habitat mapping (1:100000) prepared for Torres Strait by Stanton et al. (2008) was used to tabulate the total number of vegetation communities and habitat types on each island. In addition to total number of habitat types, we used the inverse of Simpson's index (Simpson 1949) to quantify habitat diversity. Simpson's index calculates the probability that two randomly placed points will fall in a different habitat. The inverse of Simpson's index ranges from a value of 1 , 
when there is only one habitat, to the total number of habitat types where each occupies an equal area. Thirty-four habitat types have been identified in Torres Strait, hence the maximum possible habitat diversity is also 34 .

\section{Geology and population density}

Human population data were taken from the Australian Bureau of Statistics (2007) and classification of island geology follows Willmott and Powell (1977) and Stanton et al. (2008).

\section{Data analysis}

Spearman's Rank Correlation Coefficient was used to test correlations between each of our island variables. We then tested variables against overall vertebrate richness and richness of birds, mammals, reptiles and amphibians.

We performed separate nested subset analyses for all vertebrates, birds, mammals, reptiles, frogs and habitats. Similar studies have suggested that the use of nested subset analysis as a single index to describe potentially complex patterns of species distribution is of little benefit (Woinarski et al. 2001). In the current study, we have used it to support additional analyses and in this context believe it can assist in establishing the importance of island size to species richness.

Various metrics are available to test for the presence of nested patterns (Patterson and Atmar 1986; Cutler 1991; Atmar and Patterson 1993). We chose the metric based on overlap and decreasing fill (NODF) (Almeida-Neto et al. 2008) that improves on previous estimates by calculating nestedness independently among rows and columns. Values of NODF increase with nestedness, and we calculated this using the freely available program ANINHADO 3.0 (Guimarães and Guimarães 2006).

We used the statistical program PATN ver. 3 for Windows (Belbin 1995) to group islands according to similarities in their vertebrate fauna. All species were weighted equally within our presence-absence matrix for the 17 islands. Species recorded on only one island were excluded from the metric to reduce the potential effects of unequal sampling effort between islands (Clarke and Warwick 1994). The Bray-Curtis index was used to quantify similarity between islands and clusters were derived using a flexible unweighted pair-group mean averaging (UPGMA) with a $\beta$ value of -0.1 (Belbin 1995). To test for differences in the $F$-ratio of the island association values, our classification was verified using the statistical procedure ANOSIM whereby groups were compared with 10000 iterations in which islands were randomly reallocated between groups (Clarke and Green 1988).

\section{Results}

\section{Vertebrate records}

Our surveys and desktop reviews reveal that 252 bird species, 29 mammals, 62 reptiles and 14 amphibians (357 terrestrial vertebrate species) have been recorded from the study islands. Desktop sources yielded 3363 individual species records and our surveys yielded 703 records. Of our records, 197 were new to a particular island and we increased individual island inventories by an average of $21.56 \%( \pm 11.92 \%)$. A species list of vertebrates and their island distributions is provided as supplementary material to this paper.

A large number of vertebrates ( 68 species) have been recorded from only a single island. One amphibian (Litoria caerulea), 13 birds (Charadrius mongolus, Coracina novaehollandiae, Ducula bicolor, Egretta sacra, Geopelia humeralis, Merops ornatus, Nectarinia jugularis, Numenius phaeopus, Nycticorax caledonicus, Pelecanus conspicillatus, Thalasseus bergii, Todiramphus sanctus and Tringa brevipes) and one reptile (Cryptoblepharus virgatus) have been recorded on all 17 islands. One endemic species (Carlia quinquecarinata) has been recorded (from Erub Island). Ten exotic species have been recorded, of which one is an amphibian (Rhinella marina), three are birds (Columba livia, Passer domesticus and Acridotheres tristis), four are mammals (Cervus timorensis, Mus musculus, Rattus rattus and Sus scrofa) and one is a reptile (Hemidactylus frenatus).

\section{Analysis of variables}

Spearman's Rank Correlation identified correlations between island size and almost all remaining variables. Total vegetation communities, total habitat types, and overall isolation were all correlated with island size $(P<0.01)$. Island size was also correlated with continental isolation $(P<0.05)$ and was negatively correlated with human population density $(P<0.05)$ (human populations are denser on smaller islands). Simpson's habitat diversity was not correlated with island size and values for all islands were low (ranging between 0.77 and 5.85 out of a potential maximum of 34).

Vertebrate species richness was correlated with island size, overall isolation, total vegetation communities, and total habitat types, and negatively correlated with human population density (Table 2). There was no correlation between Simpson's habitat diversity and vertebrate species richness.

Separate analyses of bird, mammal, reptile and amphibian species richness revealed mixed results (Table 2). Bird richness correlated with almost all variables, with the most significant

Table 2. Correlations between species richness and island variables (Spearman's Rank Correlation coefficients) Probability levels: n.s. $=$ not significant; ${ }^{*}, P<0.05 ; * *, P<0.01 ; * * *, P<0.001$

\begin{tabular}{|c|c|c|c|c|c|c|c|}
\hline & Island size & $\begin{array}{c}\text { Continental } \\
\text { isolation }\end{array}$ & $\begin{array}{l}\text { Overall } \\
\text { isolation }\end{array}$ & $\begin{array}{c}\text { Simpson's } \\
\text { habitat } \\
\text { diversity }\end{array}$ & $\begin{array}{c}\text { Total } \\
\text { vegetation } \\
\text { communities }\end{array}$ & $\begin{array}{c}\text { Total } \\
\text { habitat } \\
\text { types }\end{array}$ & $\begin{array}{c}\text { Human } \\
\text { population } \\
\text { density }\end{array}$ \\
\hline Vertebrates & $0.853 * * *$ & $0.580^{*}$ & $0.799 * * *$ & $0.164^{\text {n.s. }}$ & $0.830 * * *$ & $0.798 * * *$ & $-0.720 * *$ \\
\hline Birds & $0.857 * * *$ & $0.564 *$ & $0.713 * *$ & $0.029^{\text {n.s. }}$ & $0.731 * * *$ & $0.747 * * *$ & $-0.762 * * *$ \\
\hline Mammals & $0.776 * * *$ & $0.330^{\text {n.s. }}$ & $0.833 * * *$ & $0.363^{\text {n.s. }}$ & $0.731 * * *$ & $0.724 * * *$ & $-0.643 * *$ \\
\hline Reptiles & $0.546^{*}$ & $0.230^{\text {n.s. }}$ & $0.611 * *$ & $0.534 *$ & $0.656 * *$ & $0.574^{*}$ & $-0.378^{\mathrm{n} . \mathrm{s}}$ \\
\hline Amphibians & $0.642 * *$ & $0.335^{\text {n.s. }}$ & $0.668 * *$ & $0.538^{*}$ & $0.813 * * *$ & $0.717 * *$ & $-0.555^{*}$ \\
\hline
\end{tabular}


being island size, total vegetation communities and total habitat types. There was no correlation with Simpson's habitat diversity.

Mammal species richness was correlated with island size, overall isolation, total vegetation communities and total habitat types. It was not correlated with continental isolation or Simpson's habitat diversity.

Frog species richness was correlated with island size, total vegetation communities, total habitat types, overall isolation and Simpson's habitat diversity. There was no correlation with continental isolation.

Reptile richness was correlated with island size, overall isolation, total vegetation communities, total habitat types, and Simpson's habitat diversity.

\section{Nested subset analysis}

NODF analysis confirmed that all species groups are nested. Nestedness among islands $\left(\mathrm{N}_{\text {row }}\right)$ was higher than nestedness of species occupancy $\left(\mathrm{N}_{\mathrm{col}}\right)$ (Table 3$)$. Birds showed the most pronounced and mammals the least pronounced degrees of nestedness. Habitats also conform to a nested subset pattern.

\section{Cluster analysis}

The classification dendrogram separated islands into four main groups, with the island of Mabuyag identified as an outlier (Fig. 2). Islands from the same geographical location were generally clustered together (e.g. Boigu, Saibai and Dauan; Waiben, Kiriri, Muralug and Ngurupai; Mer and Erub; and Mua and Badu). In broader terms, the dendrogram separated the study islands into two main groups: islands from the Inner, Near and Top Western groups formed one cluster, while islands from the Eastern and Central groups formed the second.

\section{Discussion}

\section{Vertebrate records}

The richness of terrestrial vertebrates documented here far exceeds that reported by previous studies of the Torres Strait fauna. As an example, Draffan et al. (1983) reported 150 species of bird from throughout the Torres Strait; our review has increased this number to 252 species (and has focussed on inhabited islands only). From our limited surveys we were able to increase island inventories by an average of $21.56 \%( \pm 11.92 \%)$, highlighting the need for more thorough surveys in the region.

The physical and geographical characteristics of the Torres Strait islands suggest that a comparatively high vertebrate richness should be expected. The islands occupy a position between two large and biologically diverse landmasses and they have been isolated for a relatively short period (reaching current formations 5800 years ago) (Barham 1999; Woodroffe et al. 2000). As a result, they are potentially supersaturated with previously widespread land bridge faunas (Diamond 1972). Furthermore, many of the islands are closely grouped, several are larger than 10000 ha, and overall they support a high number of vegetation communities and habitat types. These traits have been found to sustain higher vertebrate diversity on similar continental shelf archipelagos (e.g. Lawlor 1986; Woinarski et al. 1999a, 1999b, 2001; Okie and Brown 2009).

Individual island inventories demonstrate affinities towards their closest mainland. Boigu, Saibai and Dauan support several New Guinean birds (e.g. Dicaeum geelvinkianum, Tanysiptera hydrocharis, Ptilonopus iozonus), reptiles (Pseudechis papuanus, Oxyuranus scutellatus canni), and a mammal (Pteropus macrotis) that have not been recorded elsewhere within Australia's political boundary. In comparison, fauna assemblages of the southern islands (Muralug, Kiriri, Ngurupai and Waiben) are more closely allied to those of the savannahs of Cape York Peninsula.

Endemism is limited to a single species (Carlia quinquecarinata), although it too may later prove to be present on mainland New Guinea (Donnellan et al. 2009). The lack of endemics confirms that the islands support what is a depauperate fauna of New Guinea and Australia (Schodde and Calaby 1972).

Strict quarantine regulations have largely prevented the establishment of exotic species. However, the focus has been on preventing the passage of fauna from New Guinea to Australia and the potential for the spread of species from Australia to the islands is rarely considered. Recent examples of the black rat (Rattus rattus) and the cane toad (Rhinella marina) being introduced to the islands from mainland Australia warrant a review of the current quarantine practice.

Several species remain conspicuously absent from these inventories. Two birds (Melithreptus albogularis, Chlamydera cerviniventus), five mammals (Sminthopsis virginiae, Uromys caudimaculatus, Rattus leucopus, Rattus sordidus, Petaurus breviceps), and two frogs (Limnodynastes convexiusculus, Litoria rothii) are all present on the tip of Cape York Peninsula and southern New Guinea (Grant and Leung 1993, 1994; Flannery 1995a; Higgins and Davies 1996; McNiven and Hitchcock 2004; Menzies 2006; Van Dyck and Strahan 2008), yet have not been identified from any of the study islands.

Table 3. NODF measure of nestedness for inhabited Torres Strait Islands

$\mathrm{N}_{\text {row }}$, nestedness among all rows (islands); $\mathrm{N}_{\text {col }}$, nestedness among all columns (species); NODF, total matrix nestedness; NODF(Er), nestedness of null model where presences are randomly assigned to any cell within the matrix; $\mathrm{P}(\mathrm{Er})$, significance of NODF based on this null model; NODF(Ce), nestedness of null model where the probability of a cell $a_{i j}$ showing a presence is $\left(\mathrm{P}_{\mathrm{i}} / \mathrm{C} \quad \mathrm{P}_{\mathrm{j}} / \mathrm{R}\right) / 2$, in which $\mathrm{P}_{\mathrm{i}}$ is the number of presences in the row $\mathrm{i}, \mathrm{P}_{\mathrm{j}}$ is the number of presences in the column $\mathrm{j}, \mathrm{C}$ is the number of columns and $\mathrm{R}$ is the number of rows; $\mathrm{P}(\mathrm{Ce})$, significance of NODF based on this null model

\begin{tabular}{|c|c|c|c|c|c|c|c|}
\hline & $\mathrm{N}_{\text {row }}$ & $\mathrm{N}_{\mathrm{col}}$ & NODF & NODF(Er) & $\mathrm{P}(\mathrm{Er})$ & NODF(Ce) & $\mathrm{P}(\mathrm{Ce})$ \\
\hline All vertebrates & 58.27 & 32.62 & 32.69 & 20.06 & $<0.01$ & 24.43 & $<0.01$ \\
\hline Birds & 56.88 & 34.00 & 34.11 & 21.96 & $<0.01$ & 25.95 & $<0.01$ \\
\hline Mammals & 33.46 & 17.74 & 24.70 & 9.88 & $<0.01$ & 14.72 & 0.01 \\
\hline Reptiles & 42.66 & 29.64 & 21.23 & 16.50 & 0.01 & 16.64 & $<0.01$ \\
\hline Amphibians & 58.12 & 34.55 & 51.33 & 14.00 & $<0.01$ & 26.40 & $<0.01$ \\
\hline Habitats & 43.03 & 31.13 & 33.56 & 18.07 & $<0.01$ & 23.91 & $<0.01$ \\
\hline
\end{tabular}




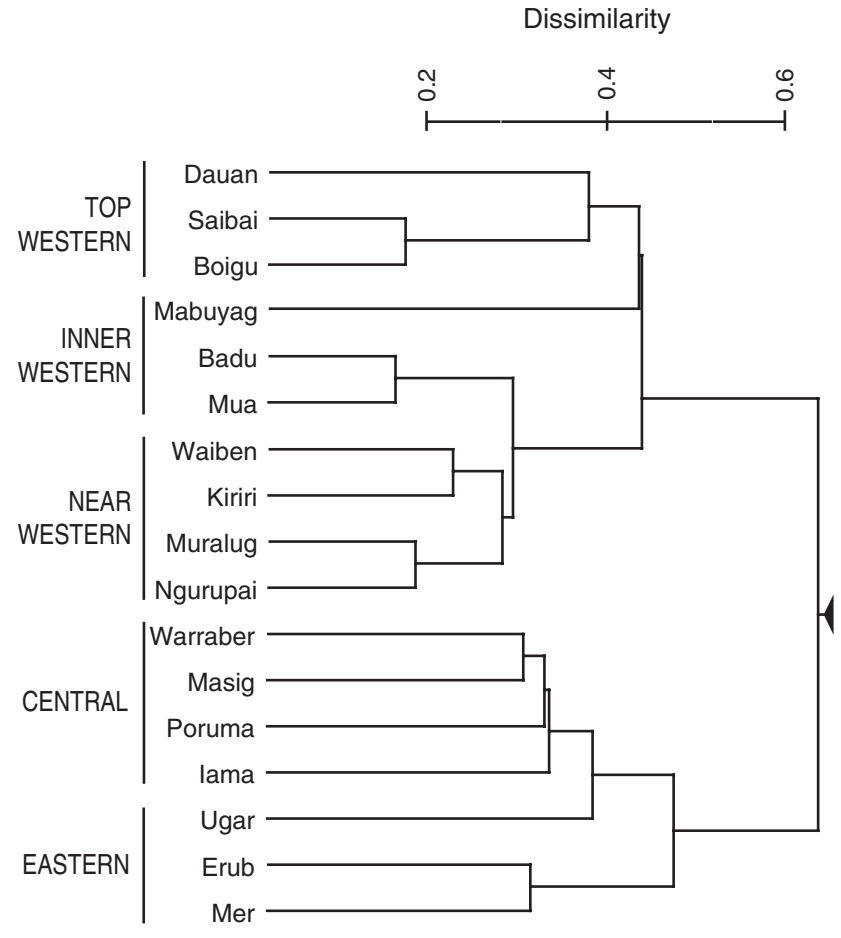

Fig. 2. Dendrogram of the Bray-Curtis dissimilarity between island vertebrate assemblages.

\section{General species richness}

The data used in this study are compiled from surveys employing a variety of methods and survey efforts, and thus present potential shortcomings. The principal of these is the comparison of species richness between islands without reference to taxon-sampling curves. Without this, any perceived differences could easily be due to inadequate sampling rather than low species richness (Gotelli and Colwell 2001). It remains likely that unrecorded species exist on all islands, and these false absences will contribute to unexplained variation in our biogeography analyses. The species records we have reviewed span almost a century from the first accounts of the Torres Strait fauna until the present. There is a continual turnover of species on islands (MacArthur and Wilson 1967) and some species listed in our inventories may have become locally extinct since the time of recording.

Distinguishing which of the variables most influence vertebrate richness is challenging given almost all are correlated with island size. The relative degree of isolation of large islands in Torres Strait is negligible and large islands also support the greatest numbers of vegetation communities and habitat types. Simpson's habitat diversity was the sole variable independent of island size. In Torres Strait, larger islands are often spatially dominated by a limited number of habitat types. Additional habitats occur as small patches and thus contribute little to Simpson's measure of diversity. Of the six largest islands, Boigu and Saibai support 12 and 14 habitat types respectively, yet a single habitat (Mangrove communities) dominates $81 \%$ and $63 \%$ of island areas. Badu, Mua, Muralug and Ngurupai support up to 20 habitat types, yet just four of these make up between $73 \%$ and $90 \%$ of total island areas. Species richness of all groups were correlated with the total number of habitat types. However, only reptiles and amphibians were weakly correlated with Simpson's habitat diversity. This suggests that small areas of uncommon habitats may be disproportionately important for vertebrates in Torres Strait. For example, wetland complexes and mosaics are present as relatively small areas on larger islands but support a large number of waterbirds and amphibians that do not persist in the absence of these habitats.

Nested analysis confirmed that both the vertebrate species and habitats found on small islands are subsets of those occurring on larger islands. This is common for land bridge archipelagos and is evidence of a strong area effect (Patterson and Atmar 1986; Wright et al. 1997; Meyer and Kalko 2008). Confirmation of a nested pattern in habitats indicates that those rare habitats that appear disproportionately important for species richness occur on larger islands. The nested pattern we observed in birds may also be a reflection of nested habitats to some degree. For example, Atmar and Patterson (1993) identified that nested patterns in migratory species observed by Simberloff and Martin (1991) were a result of their annual settlement in a pattern dictated by the nested structure of appropriate habitats rather than the birds themselves.

Similarities in vertebrate assemblages according to geographical location were evident from our cluster analysis. Assemblages present on smaller, remote islands of the Eastern and Central groups are more impoverished than those of the less isolated Inner, Near and Top Western groups. The influence of New Guinea on Top Western islands was indicated by the grouping of Dauan (a smaller continetal island) with Boigu and Saibai (two much larger mud islands).

\section{Birds}

Draffan et al. (1983) suggested that the availability of woodland vegetation was the most significant influence on bird species richness in Torres Strait. At a $50 \mathrm{~m} \times 50 \mathrm{~m}$ quadrat level, Woinarski et al. (2001) confirmed similar patterns on Arnhem Land islands, whereby species richness was most influenced by the type of vegetation present. However, at an archipelago-wide scale, island size was clearly the most important predictor of species richness. This was attributed to larger islands accumulating a broader range of habitats and an increased potential for the occurrence of rarer species. From our data, it appears that a similar relationship may exist in Torres Strait. Our use of more detailed vegetation mapping has obscured any patterning in response to a single community. However, we detected a correlation between bird species richness and the total number of vegetation communities and habitat types that accumulate with increases in island size.

Torres Strait provides suitable habitat for many migratory species. Most international migratory shorebirds known to occur in Australia have been recorded from our study islands and many of these also act as crucial stopovers for seasonal migrants that travel between Australia and New Guinea (Draffan et al. 1983).

Draffan et al. (1983) raised concerns about the potential for spread of introduced avian species throughout Torres Strait. At the time of publication, they reported the presence of three exotic species (Columba livia, Passer domesticus, Acridotheres tristis). Our data show no additional exotic bird species, although two of these species ( $P$. domesticus and A. tristis) have spread to 
islands in addition to those reported by Draffan et al. (1983). Australian quarantine measures have placed great emphasis on bird monitoring as a precaution against the introduction of avian diseases and this has likely prevented the introduction of additional exotic species.

\section{Mammals}

We have treated the mammalian fauna as a single grouping, but it is likely there are differences in distributional patterning between volant and non-volant groups. In a review of insular mammals worldwide, Lawlor (1986) determined that the patterns of distribution of bats conformed to the equilibrium theory (MacArthur and Wilson 1967). Conversely, non-volant species on continental shelf islands were shown to be extinction limited, where species richness is dictated by rates of extinction as species are lost with sea level rise and reductions in island area. Small mammal datasets are typically nested because of a relative ease of insularisation (Atmar and Patterson 1993) and island area effects have been shown for non-volant mammals on comparable landbridge archipelagos (Meyer and Kalko 2008; Okie and Brown 2009). Similarly, in Torres Strait, non-volant mammals are concentrated on the larger islands with only a single native species inhabiting the smaller Central and Eastern islands.

For bats, also, the greatest species richness is found on the larger western islands. However, it is evident that at least one species (Pteropus alecto) transits between Australia and New Guinea (Breed et al. 2010), and is capable of reaching more remote islands. During this study $P$. alecto was recorded on the remote Central islands (Poruma and Warraber) and was also reported to visit Mer in the Eastern group when the abundant mango trees are in fruit (D. Passi, pers. comm.). An additional two species of Pteropus are confirmed from the study islands (P. macrotis, P. scapulatus). The status of $P$. macrotis in the Torres Strait was challenged by Helgen (2004) as his examination of specimens from Mua revealed they were, in fact, $P$. scapulatus that had been misidentified. Subsequent to that review, however, P. macrotis was again added to the Australian vertebrate list following confirmation of its presence on Boigu and Saibai islands (Hall 2008). A fourth species (P. conspicillatus) is also reported to occur in Torres Strait (Clague et al. 1999; Helgen 2004). However, our reviews of the literature and databases have failed to confirm any records of this species on the study islands.

The identities of tube-nosed bats (Nyctimene spp.) in Torres Strait have been subject to some confusion. Both $N$. robinsoni and $N$. cephalotes have been reported from Mua Island. However, our examination of $N$. cephalotes specimens held within the Australian National Wildlife Collection (Canberra, Australia) and Queensland Museum (Brisbane, Australia) suggests that they are, in fact, $N$. robinsoni. A recent taxonomic review of the subfamily Nyctimeninae throughout Melanesia, Australia and south-east Asia (including specimens from Mua) has also implied that $N$. cephalotes is not present within Australia (N. Irwin, pers. comm.).

Melomys specimens previously identified as M. lutillus (Ingram and Caneris 2004) on Dauan have now been conclusively determined to be $M$. burtoni (Bryant et al.2011). Our examination of Melomys from the islands closest to Bramble Cay (Mer, Erub and Ugar) indicates that these too are M. burtoni and not M. rubicola, as has been raised as a possibility (Latch 1998). M. burtoni, a species that prefers open savannahs and grasslands to denser vegetation communities (Kerle 2008), is thus the most widespread mammal in Torres Strait. The predominance of this native rodent and relative absence of typical rainforest species (e.g. M. capensis) supports the hypothesis that the Sahul land bridge was dominated by drier vegetation communities during the Pleistocene (Nix and Kalma 1972).

The record of the Pacific rat (Rattus exulans) on Mer is intriguing, stemming from an undated specimen collected by A. C. Haddon and presented to the British Museum of Natural History in 1899 (Taylor and Horner 1973). However, there have been no records since that time, nor from intensive trapping carried out over the past three years as part of an exotic rodent eradication project on the island.

The record of the water rat (Hydromys chrysogaster) on Badu is derived from a road-kill specimen that was badly decayed, rendering the skull and skin unavailable for collection. Recovered hair samples were deemed to be highly unusual for H. chrysogaster, such that the possibility that the specimen was either a subspecies or a new Australian species of Hydromys was raised (B. Triggs, pers. comm.).

The use of an Anabat II unit enabled us to identify one species of bat (Myotis macropus) previously unknown from Torres Strait. Several more previously unrecorded species (e.g. forest pipistrelle, Pipistrellus adamsi; northern pipistrelle, $P$. westralis) were also detected; however, uncertainties with call identification and possible confusion with other species meant we were unable to include them in the inventories. Additional methods for bat surveys, such as harp traps and trip lines, were not used in this study and it is certain that should such survey methods be employed, further species could be added to fauna inventories.

Flannery (1995b) suggested that long-term rates of persistence of marsupials on islands are lower than for placental mammals. Indeed the marsupial fauna of Torres Strait is notably depauperate, with only two species having been recorded. A single species of macropod (Macropus agilis) is known from Muralug and two small islands not included in this study (McNiven 2008) and remains are also known from Mua (Ingram 2008). The population on Muralug appears to have perished, possibly as a result of hunting and wild dogs (Moore 1979). Whether the remains recorded from Mua stem from a previously existing viable population or are the result of human translocations remains cause for debate (Moore 1979; McNiven 2008). The second species of marsupial is the northern brown bandicoot (Isoodon macrourus). This was only recently observed on Mua (Conics Pty Ltd 2009; Hitchcock et al., in press), highlighting the need for more thorough inventories of mammals on the larger islands.

\section{Reptiles}

A general pattern for reptiles is difficult to interpret from our results. Previous studies of Torres Strait reptiles (Cameron et al. 1984) concluded that assemblages are linked with island geology and associated vegetation communities. Yet on similar, continental shelf archipelagos Woinarski et al. (1999a) found a strong relationship between island size and species richness. 
Our inventories demonstrate a more irregular distribution for reptiles than for any other taxa and taxonomic uncertainty is also greater among this group. More specimens were identified using superseded synonyms, genus alone, or to confer (cf.) with certain species than for any other group. Twelve of the 69 species (Carlia quinquecarinata, Chelodina rugosa, Cryptophis incredibilis, Demansia papuensis, Fordonia leucobalia, Oxyuranus scutellatus canni, Pseudechis australis, Pseudechis papuanus, Ramphotyphlops polygrammicus, Ramphotyphlops wiedii, Stegonotus parvus and Tropidonophis mairii) have single-island distributions. Taxonomic uncertainties coupled with the large proportion of species with limited distributions suggest that reptiles may be the most undersurveyed fauna in Torres Strait. The inadequacies of reptile distributional data in this region are highlighted by the emerald monitor (Varanus prasinus). This large, visually striking species has previously been cited as occurring on six islands (Boigu, Dauan, Mabuyag, Mer, Mua and Saibai) (Borsboom 2007). On two islands (Boigu and Mua), the presence of the species is unequivocal from this study and from Whittier and Moeller (1993), Clarke (2004a) and Ingram (2008). The remaining records stem from unconfirmed WildNet sighting records, and are difficult to verify. One of these (Mer) is a small island that has been intensively surveyed throughout 2009-12 for an exotic rodent eradication project and no indication of $V$. prasinus has yet been detected (R. Diete, pers. comm.). Consultation with Mer Island residents also indicates that the species has never occurred there. In contrast, residents of Badu (an island not listed by Borsboom (2007)) were adamant that $V$. prasinus resides there. Such false absences and presences are likely to be even more common amongst cryptic species of reptile.

Much uncertainty also surrounds specimens of Gehyra dubia and $G$. bailiola collected from the islands. Those from Inner Western islands (Mua and Badu) were identified conclusively by the Queensland Museum as G. dubia. However, specimens collected from the Central group of islands were identified inconclusively as either Gehyra cf. dubia or Gehyra sp. King et al. (1989) reviewed the status of G. baliola and determined that, within Australia, the species was restricted to Erub and Mer Islands. Additional specimens collected during these surveys from Saibai, Dauan and Iama also resembled G. bailiola, but we were not able to conclusively identify them as this species. It is clear that further morphological examination of Gehyra specimens is necessary to determine the distribution of species from this genus throughout Torres Strait.

Mer Island, although being one of the most isolated islands, has exceptional reptile diversity ( 28 species). This includes at least one species (Stegonotus parvus) widespread in lowland New Guinea but recorded nowhere else in Australia (Wilson and Swan 2010). The influence of New Guinea on the reptiles of the eastern islands has been previously noted (Donnellan et al. 2009) and special consideration should be given for this influence and the high reptile diversity present on Mer as part of any future conservation planning for the region.

The record of Emydura subglobosa on Erub stems from an old specimen held by the Queensland Museum. The specimen is a hatchling collected sometime before 1910 and of very uncertain provenance. It is probably best disregarded as Erub does not support suitable wetland habitats and the specimen was quite possibly collected elsewhere.

Australian populations of amethyst pythons (Morelia kinghorni) were separated from those of New Guinea (M. amethistina) by Harvey et al. (2000). Unfortunately, these authors did not address distributions of either species in Torres Strait, and no discussion of morphological characters separating the two was provided. For the purposes of this study, all Torres Strait specimens have been referred to M. kinghorni; however, neither the presence of $M$. amethistina nor absence of $M$. kinghorni in the region can be conclusively stated.

\section{Amphibians}

Amphibians are extremely poor at dispersersing across oceanic barriers (Cameron et al. 1984) and islands that have been subject to a period of recent biotic destruction (for example, inundation of coral cays by salt water) are typically devoid of frogs (Thornton et al. 1990). Thus, the assemblages recorded on continental shelf islands are most likely those that were present at the time of isolation or at least a subset of those (e.g. Woinarski et al. 1999a). Amphibian species richness sharply declines outside the larger Western islands, with the peak of diversity (17 species) recorded on Mua in the Near Western group.

Only a single species (Litoria caerulea) is encountered on coral cays and remote eastern islands in Torres Strait. Anecdotal reports suggest that on at least two islands (Ugar and Warraber) the presence of the species is as a result of accidental introduction by supply barge, and that the species was also intentionally introduced to Masig.

The most interesting amphibian record is one of a Papuan frog (Rana papua) collected from Mer during the Hedley and McCulloch expedition in 1907. If the specimen is, indeed, $R$. papua, it is highly significant, being both the first record of this species and only the second species of ranid frog (Anura: Ranidae) in Australia. It is possible that the record, in fact, pertains to the wood frog (Sylvirana daemeli) (collected from Torres Strait for the first time during this study). However, distinguishing between preserved material of these two species is difficult, especially given the age of the Mer specimen. Examination by museum experts was unable to conclusively assign it to $R$. papua or $S$. daemeli and extensive searches of Mer have thus far been unable to confirm the presence of the species. Continued searches and additional examinations of the museum specimen are warranted.

\section{Conclusions}

This study provides a baseline account of terrestrial vertebrate richness on the 17 inhabited Torres Strait islands. Our data support previous reports that the fauna of Torres Strait is essentially a depauperate subset of that found on Cape York Peninsula and southern New Guinea. Although the true role of physical island variables cannot be conclusively determined, island size (coupled with the richness of habitat types and vegetation communities) provides a useful mechanism for predicting island species richness. Larger islands support a greater number of vegetation communities and habitats, including those that are rare throughout the region. It appears that these rarer vegetation communities may have great importance for 
maintaining higher vertebrate richness. It is certain that additional species remain to be documented and it is on larger islands where searches for these should be focussed. All future sampling should employ taxon sampling curves to determine the adequacy of survey effort (e.g. Thompson and Thompson 2007).

\section{Acknowledgements}

Island Prescribed Body Corporate bodies, Island Councils and the people of Badu, Boigu, Dauan, Erub, Iama, Kiriri, Mabuyag, Mer, Masig, Mua, Ngurupai, Poruma, Saibai, Ugar, Waiben and Warraber Islands are thanked for their kind hospitality and access to traditional lands. Fauna surveys were funded by the Torres Strait Regional Authority (TSRA), care of Natural Heritage Trust and Australian Federal Government grants. Survey team members were Sarah Drayton, Mark Free, Simon Gleed, Garrick Hitchcock, Melissa Jess, Vivian Seto and Cameron Slack. Rebecca Diete and Natalie Waller also contributed incidental records. These people are sincerely thanked for their dedication in the field. Andrew Amey, Patrick Couper, Heather Janetzki, Steve Van Dyck and Jodi Rowley provided invaluable assistance and advice with the identification of vertebrate species. Allan Lisle and Andrew Olds provided advice on statistical analyses. Thank you to Greg Ford for bat call analysis and Barbara Triggs for hair analysis. Many researchers have contributed to the state government, museum and literature records presented here.

\section{References}

Almeida-Neto, M., Guimarães, P., Guimarães, P. Jr., Loyola, R., and Ulrich, W. (2008). A consistent metric for nestedness analysis in ecological systems: reconciling concept and measurement. Oikos 117, 1227-1239. doi:10.1111/j.0030-1299.2008.16644.x

Atmar, W., and Patterson, B. (1993). The measure of order and disorder in the distribution of species in fragmented habitat. Oecologia 96, 373-382. doi:10.1007/BF00317508

Australian Bureau of Statistics. (2007). 2006 Census Data. Australian Bureau of Statistics, Canberra

Barham, A. (1999). The local environmental impact of prehistoric populations on Saibai Island, northern Torres Strait, Australia: enigmatic evidence from Holocene swamp lithostratigraphic records. Quaternary International 59, 71-105. doi:10.1016/S1040-6182(98)00073-1

Belbin, L. (1995). 'PATN Technical Reference.' (CSIRO Division of Wildlife and Ecology: Canberra.)

Borsboom, A. (2007). Nomination to re-classify the 'rare' Varanus prasinus to 'near threatened' under the Nature Conservation Act 1992. Queensland Environmental Protection Agency.

Breed, A. C., Field, H. E., Smith, C. S., Edmonston, J., and Meers, J. (2010). Bats without borders: long-distance movements and implications for disease risk management. EcoHealth 7, 204-212. doi:10.1007/s10393010-0332-Z

Brown, J. (1971). Mammals on mountaintops: nonequilibrium insular biogeography. American Naturalist 105, 467-478. doi:10.1086/282738

Bryant, L. M., Donnellan, S. C., Hurwood, D. A., and Fuller, S. J. (2011). Phylogenetic relationships and divergence date estimates among Australo-Papuan mosaic-tailed rats from the Uromys division (Rodentia: Muridae). Zoologica Scripta 40, 433-447. doi:10.1111/j.1463-6409. 2011.00482.x

Burbidge, A., Williams, M., and Abbott, I. (1997). Mammals of Australian islands: factors influencing species richness. Journal of Biogeography 24, 703-715. doi:10.1046/j.1365-2699.1997.00145.x

Cameron, E., Cogger, H., and Heatwole, H. (1984). Torres Strait: a natural laboratory. In 'Vertebrate Zoogeography and Evolution in Australia'. (Eds M. Archer and G. Clayton.) pp. 1151-1155. (Hesperian Press: Carlisle.)

Christidis, L., and Boles, W. (2008). 'Systematics and Taxonomy of Australian Birds.' (CSIRO Publishing: Melbourne.)
Clague, C., Freeman, A., Garnett, S., Spencer, H., Whybird, O., and Richards, G. (1999). Spectacled flying-fox, Pteropus conspicillatus. In 'The Action Plan for Australian Bats'. (Eds A. Duncan, G. B. Baker and N. Montgomery.) pp. 44-45. (Environment Australia: Canberra.)

Clarke, K., and Green, R. (1988). Statistical design and analysis for a 'biological effects' study. Marine Ecology Progress Series 46, 213-226. doi: $10.3354 /$ meps 046213

Clarke, K., and Warwick, R. (1994). 'Change in Marine Communities: an Approach to Statistical Analysis and Interpretation.' (Natural Environment Research Council, Plymouth Marine Laboratory: Plymouth, UK.)

Clarke, R. (2004a). A record of the emerald monitor Varanus prasinus from Boigu Island, Torres Strait, Australia. Herpetofauna 34, 70-71.

Clarke, R. (2004b). The avifauna of northern Torres Strait: notes on a wet season visit. Australian Field Ornithology 21, 49-66.

Clarke, R. (2006). Papuan spine-tailed swifts Mearnsia novaeguineae on Boigu Island, Torres Strait, Queensland. Australian Field Ornithology 23, 125-129.

Clarke, R. (2007). An orange-bellied fruit-dove Ptilinopus iozonus on Boigu Island, Torres Strait: the first record for Australian territory. Australian Field Ornithology 24, 44-48.

Clarke, R., Gosford, R., Boyle, A., Sisson, L., and Ewen, J. (2010). A specimen record of the little paradise-kingfisher Tanysiptera hydrocharis from Torres Strait, Queensland: a new bird for Australian territory. Australian Field Ornithology 27, 165-173.

Conics Pty Ltd. (2009). Habitat and Fauna Assessment-St Pauls Community, Moa Island. Unpublished report to TSRA Land \& Sea Management Unit.

Cutler, A. (1991). Nested faunas and extinction in fragmented habitats. Conservation Biology 5, 496-504. doi:10.1111/j.1523-1739.1991. tb00357.x

Diamond, J. (1972). Biogeographic kinetics: estimation of relaxation times for avifaunas of southwest Pacific islands. Proceedings of the National Academy of Sciences of the United States of America 69, 3199-3203. doi:10.1073/pnas.69.11.3199

Diver, K. (2008). Not as the crow flies: assessing effective isolation for island biogeographical analysis. Journal of Biogeography 35, 1040-1048. doi:10.1111/j.1365-2699.2007.01835.x

Donnellan, S., Couper, P., Saint, K., and Wheaton, L. (2009). Systematics of the Carlia 'fusca' complex (Reptilia: Scincidae) from northern Australia. Zootaxa 2227, 1-31.

Draffan, R., Garnett, S., and Malone, G. (1983). Birds of the Torres Strait: an annotated list and biogeographical analysis. Ети 83, 207-234. doi:10.1071/MU9830207

Fernández-Juricic, E. (2002). Can human disturbance promote nestedness? A case study with breeding birds in urban habitat fragments. Oecologia 131, 269-278. doi:10.1007/s00442-002-0883-y

Flannery, T. (1995a). 'The Mammals of New Guinea.' (Cornell University Press: Ithaca, NY.)

Flannery, T. (1995b). 'Mammals of the South-west Pacific and Moluccan Islands.' (Reed Books: Sydney.)

Gotelli, N., and Colwell, R. (2001). Quantifying biodiversity: procedures and pitfalls in the measurement and comparison of species richness. Ecology Letters 4, 379-391. doi:10.1046/j.1461-0248.2001.00230.x

Grant, J., and Leung, L. K.-P. (1993). Wet Season Terrestrial Fauna Survey of the Lockerbie Scrub, Cape York Peninsula. A report to the Queensland Department of Environment and Heritage.

Grant, J., and Leung, L. K.-P. (1994). Storm Season Terrestrial Fauna Survey of the Lockerbie Scrub, Cape York Peninsula. A report to the Queensland Department of Environment and Heritage.

Guimarães, P., and Guimarães, P. (2006). Improving the analyses of nestedness for large sets of matrices. Environmental Modelling \& Software 21, 1512-1513. doi:10.1016/j.envsoft.2006.04.002

Hall, L. (2008). Large-eared flying-fox Pteropus macrotis. In 'The Mammals of Australia'. (Eds S. Van Dyck and R. Strahan.) pp. 441-442. (Reed New Holland: Sydney.) 
Harvey, M. B., Barker, D. G., Ammerman, L. K., and Chippindale, P. T. (2000). Systematics of pythons of the Morelia amethistina complex (Serpentes: Boidae) with the description of three new species. Herpetological Monograph 14, 139-185. doi:10.2307/1467047

Heaney, L. R. (1984). Mammalian species richness on islands on the Sunda Shelf, southeast Asia. Oecologia 61, 11-17. doi:10.1007/BF00379083

Helgen, K. (2004). On the identity of flying-foxes, genus Pteropus (Mammalia: Chiroptera), from islands in the Torres Strait, Australia. Zootaxa 780, 1-14.

Higgins, P., and Davies, S. (Eds) (1996). 'Handbook of Australian, New Zealand and Antarctic Birds. Volumes 1-7.' (Oxford University Press: Melbourne.)

Hitchcock, G., Conaty, S., Fell, D., Gordon, G., Reis, T., and Stanton, D. (in press). Range extension of the short-beaked echidna Tachyglossus aculeatus (Monotremata: Tachyglossidae) and the northern brown bandicoot Isoodon macrourus (Marsupialia: Peramelidae) in Queensland: Mua (Moa Island), Torres Strait. Memoirs of the Queensland Museum, in press.

Ingram, G. (2008). The terrestrial vertebrates of Mua, western Torres Strait. Memoirs of the Queensland Museum Cultural Heritage Series 4, 619-628.

Ingram, G., and Caneris, C. (2004). Fauna assessment report: high frequency surface wave extended coastal area radar (SECAR) and DSTO projects, Dauan Island, Torres Strait. A report to Daronmont Technologies. Biodiversity Assessment and Management Pty Ltd.

Keppel, G., Buckley, Y. M., and Possingham, H. P. (2010). Drivers of lowland rain forest community assembly, species diversity and forest structure on islands in the tropical South Pacific. Journal of Ecology 98, 87-95. doi:10.1111/j.1365-2745.2009.01595.x

Kerle, J. (2008). Grassland melomys Melomys burtoni. In 'The Mammals of Australia'. (Eds S. Van Dyck and R. Strahan.) pp. 667-669. (Reed New Holland: Sydney.)

King, M., Sadlier, R., and Horner, P. (1989). A note on the status of Gehyra baliola (Duméril and Duméril, 1851) in Australia. The Beagle 6, 163-167.

Latch, P. (1998). Recovery plan for the Bramble Cay melomys Melomys rubicola. Report to the Department of Environment, Water, Heritage and the Arts, Canberra. Queensland Environmental Protection Agency, Brisbane.

Lawlor, T. (1986). Comparative biogeography of mammals on islands. Biological Journal of the Linnean Society. Linnean Society of London 28, 99-125. doi:10.1111/j.1095-8312.1986.tb01751.x

Leary, T., and Pennay, M. (2011). Echolocation calls of eight microchiroptera from Papua New Guinea. In 'The Biology and Conservation of Australasian Bats'. (Eds B. Law, P. Eby, D. Lunney and L. Lumsden.) pp. 106-127. (Royal Zoological Society of New South Wales: Mosman)

MacArthur, R. H., and Wilson, E. O. (1967). 'The Theory of Island Biogeography.' (Princeton University Press: Princeton, NJ.)

Mayr, E., and Diamond, J. (2001). 'The Birds of Northern Melanesia: Speciation, Ecology \& Biogeography.' (Oxford University Press: New York.)

McNiven, I. (2008). Inclusions, exclusions and transitions: Torres Strait islander constructed landscapes over the past 4000 years, northeast Australia. The Holocene 18, 449-462. doi:10.1177/0959683607087934

McNiven, I., and Hitchcock, G. (2004). Torres Strait islander marine subsistence specialisation and terrestrial animal translocation. Memoirs of the Queensland Museum Cultural Heritage Series 3, 1-59.

Menkhorst, P., and Knight, F. (2004). 'A Field Guide to the Mammals of Australia.' (Oxford University Press: Melbourne.)

Menzies, J. (2006). 'The Frogs of New Guinea and the Solomon Islands.' (Pensoft Publishers: Sofia.)

Meyer, C., and Kalko, E. (2008). Bat assemblages on Neotropical land-bridge islands: nested subsets and null model analyses of species co-occurrence patterns. Diversity \& Distributions 14, 644-654. doi:10.1111/j.14724642.2007.00462.x
Milne, D. (2002). Key to the Bat Calls of the Top End of the Northern Territory. Parks and Wildlife Commission of the Northern Territory, Darwin. Technical Report No. 71.

Mitchell, P. (1988). Unusual sighting reports. Series 68. Bird Observer 674, 38-39.

Moore, D. (1979). 'Islanders and Aborigines at Cape York.' (Australian Institute of Aboriginal Studies: Canberra.)

Niland, D. (1996). Additional birds for Moa Island, Torres Strait. The Sunbird 26, 19.

Nix, H., and Kalma, J. (1972). 'Climate as a dominant control in the biogeography of northern Australia and New Guinea.' (ANU Press: Canberra.)

Okie, J., and Brown, J. (2009). Niches, body sizes, and the disassembly of mammal communities on the Sunda Shelf islands. Proceedings of the National Academy of Sciences of the United States of America 106, 19679-19684. doi:10.1073/pnas.0901654106

Patterson, B., and Atmar, W. (1986). Nested subsets and the structure of insular mammalian faunas and archipelagos. Biological Journal of the Linnean Society. Linnean Society of London 28, 65-82. doi:10.1111/ j.1095-8312.1986.tb01749.x

Queensland Department of Environment and Heritage Protection. (2012). WildNet (Database). Queensland Department of Environment and Heritage Protection: Brisbane.

Reinhold, L., Law, B., Ford, G., and Pennay, M. (2001). 'Key to the Bat Calls of South-east Queensland and North-east New South Wales.' (Department of Natural Resources and Mines: Brisbane.)

Schodde, R., and Calaby, J. (1972). The biogeography of the Australo-Papuan bird and mammal faunas in relation to Torres Strait. In 'Bridge and Barrier: the Natural and Cultural History of Torres Strait'. (Ed. D. Walker.) pp. 257-300. (Australian National University: Canberra.)

Simberloff, D., and Martin, J. (1991). Nestedness of insular avifaunas: simple summary statistics masking complex species patterns. Ornis Fennica 68, 178-192.

Simpson, E. H. (1949). Measurement of diversity. Nature 163, 688. doi:10.1038/163688a0

Stanton, D., Fell, D., and Gooding, D. (2008). Vegetation communities and regional ecosystems of the Torres Strait islands - an accompaniment to land zone, vegetation community and regional ecosystem maps. Unpublished report to TSRA Land \& Sea Management Unit.

Sutherland, W. (2006). 'Ecological Census Techniques: a Handbook.' 2nd edn. (Cambridge University Press: Cambridge \& New York.)

Taylor, J., and Horner, B. (1973). Results of the Archibold Expeditions. No. 98 Systematics of native Australian Rattus (Rodentia, Muridae). Bulletin of the American Museum of Natural History 150, 11-15.

Thompson, G., and Thompson, S. (2007). Using species accumulation curves to estimate trapping effort in fauna surveys and species richness. Austral Ecology 32, 564-569. doi:10.1111/j.1442-9993.2007.01728.x

Thornton, I., New, T., Zann, R., and Rawlinson, P. (1990). Colonization of the Krakatau islands by animals: a perspective from the 1980s. Philosophical Transactions of the Royal Society of London, Series B 328, 131-165. doi:10.1098/rstb.1990.0112

Van Dyck, S., and Strahan, R. (2008). 'The Mammals of Australia.' (Reed New Holland: Sydney.)

Whittier, J., and Moeller, D. (1993). Varanus prasinus (the emerald goanna) on Moa Island, Torres Strait, Australia. Memoirs of the Queensland Museum 34, 130.

Willmott, W. (1972). 1:250000 Geological Series - Explanatory Notes, Daru-Maer. (Bureau of Mineral Resources, Geology and Geophysics. Australian Government Publishing Service: Canberra)

Willmott, W. F., and Powell, B. S. (1977). Torres Strait-Boigu-Daru, Queensland 1:250000. In 'Geological Series - Explanatory Notes, Sheets SC/54-12, SC/54-7 and SC/54-8.' (Bureau of Mineral Resources, Geology and Geophysics. Australian Government Publishing Service: Canberra.) 
Wilson, S., and Swan, G. (2010). 'A Complete Guide to Reptiles of Australia.' 3rd edn. (Reed New Holland: Sydney.)

Woinarski, J. (2010). Biodiversity conservation in tropical forest landscapes of Oceania. Biological Conservation 143, 2385-2394. doi:10.1016/ j.biocon.2009.12.009

Woinarski, J., Horner, P., Fisher, A., Brennan, K., Lindner, D., Gambold, N., Chatto, R., and Morris, I. (1999a). Distributional patterning of terrestrial herpetofauna on the Wessel and English Company Island groups, northeastern Arnhem Land, Northern Territory, Australia. Australian Journal of Ecology 24, 60-79. doi:10.1046/j.1442-9993.1999.00947.x

Woinarski, J., Palmer, C., Fisher, A., Southgate, R., Masters, P., and Brennan, K. (1999b). Distributional patterning of mammals on the Wessel and English Company Islands, Arnhem Land, Northern Territory, Australia. Australian Journal of Zoology 47, 87-111. doi:10.1071/ZO99004
Woinarski, J., Fisher, A., Brennan, K., Morris, I., and Chatto, R. (2001). Patterns of bird species richness and composition on islands off Arnhem Land, Northern Territory, Australia. Austral Ecology 26, 1-13.

Woodroffe, C., Kennedy, D., Rasmussen, C., and Smithers, S. (2000). Holocene reef growth in Torres Strait. Marine Geology 170, 331-346. doi:10.1016/S0025-3227(00)00094-3

Wright, D., Patterson, B., Mikkelson, G., Cutler, A., and Atmar, W. (1997). A comparative analysis of nested subset patterns of species composition. Oecologia 113, 1-20. doi:10.1007/s004420050348

Handling Editor: Steve Cooper 